\title{
Experiencing our Town
}

\author{
In the words of immigrant women
}

AIMEE ZOELLER, GEORGE TOWERS, AND KATHERINE WILLS

\section{Authors}

\section{AIMEE ZOELLER}

Lecturer, Director of Sociology Program and Coordinator of Women, Gender, \& Sexuality Studies Minor, Indiana University Purdue University Columbus

\section{GEORGE TOWERS}

Head, Division of Liberal Arts, Professor of Geography, Indiana University Purdue University Columbus

\section{KATHERINE WILLS} Program Director and Professor, English, Indiana University Purdue University Columbus

\section{Contributors}

BRANDI RUND

Senior Business Analyst with IT Community Partnerships, Indiana University Bloomington

\section{ANNA F. CARMON}

Associate Professor and Program Director, Communication Studies, Indiana University Purdue University Columbus

\section{MATT ROTHROCK}

Coordinator, Academic Resource Center, Indiana University Purdue University Columbus

\section{DOUGLAS GARDNER}

Lecturer and Program Coordinator, History, Indiana University Purdue University Columbus
Immigrant women in Columbus, Indiana, expressed anxiety and fear in the aftermath of the 2016 U.S. presidential election and 2017 travel bans. Their concerns were highlighted in a National Public Radio (NPR) segment:

"The Sudanese-American citizens who live in a big, airy house a short drive from the Cummins plant, where husband, Khalidd Eleawad, is an engineer. About 1,400 of the company's 9,500 local workers, or 15 percent, were hired on $\mathrm{H}-1 \mathrm{~B}$ visas. Right now, [Dalia] Mohamed says her family is in limbo. They usually visit Sudan in the winter, then fly their Sudanese relatives to Indiana in the summer - but with so much uncertainty around President Donald Trump's now on-hold immigration order, which targets Sudan and six other countries, they don't want to risk it. Mohamed is Muslim and wears a hijab. She says the changes she's noticed in town since Trump's inauguration are palpable. 'I don't go out that much after Jan. 20, because my friends, they have been through so many harassments, so - so that's why I just kind of stay home,' she says" (Ropiak, 2017i).

The nation had turned their eye towards Columbus for two primary reasons: Columbus is Vice President Mike Pence's hometown and is the headquarters of the Fortune 200 diesel engine manufacturer Cummins Engine. Similar to affluent suburban communities, though situated in a mostly rural community, Columbus is not the traditional small Midwestern American town. Yet, in other ways, such as its closely held governmental and business power organized by longstanding families, it is very much a small town. Columbus is a microcosm of Silicon Valley in its per capita output, manufacturing and tech startups, as well as international workers and scholars. Columbus has attracted the spouses and families of immigrants. Columbus stands out in Indiana for the relative size of its foreign-born population. As of 2015, the city's 5,224 immigrants comprised $11.4 \%$ of the population. In contrast, only $6.6 \%$ of Indiana residents were foreign-born in 2015. The exceptional size of our immigrant community is a new development: the number of our foreign-born neighbors grew by $54 \%$ from 2010 to 2015.

Indiana University - Purdue University Columbus faculty and staff were motivated to engage in purposeful community conversations in order to support the women's urgent need to address current rhetoric concerning immigrant work and everyday lived experiences. This work was also inspired by the digital model of Humans of New York and by community literacy projects defined by the Community Literacy Journal as the "collaboration between academ- 
ics and community members, organizers, activists, teachers, and artists" (Community Literacy Journal homepage). The IUPUC team secured a Welcoming Community Arts and Culture grant from the Heritage Fund - the Community Foundation of Bartholomew County to form an interdisciplinary, intersectional community literacy project that focused on capturing narratives of refugee/immigrant women in their words. The team identified three key outcomes, as specified by the grant: "broader and more inclusive participation from diverse groups and individuals," "increase[d] understanding/appreciation of cultural differences and commonalities," and "diversity is showcased and strengthened through productions/ exhibitions." As measured through student and public surveys, and most importantly, participant feedback, all outcomes were joyfully met.

Participants were recruited through community network email listservs such as the Columbus Area Multi-Ethnic organization (CAMEO). More than a dozen immigrant women expressed interested in the project; ten participated in two "writing in your own voice" workshops hosted by IUPUC faculty and staff at the Bartholomew County Library. Childcare was provided during both workshops. Six of the women are from Mexico, three from India, and one from Colombia. One of the Mexican women is from a family of Chinese immigrants to Mexico. Similarly, participants range in age and residency in the US. For example, one of the women is 22 years old and has lived in Columbus since she was 3. Two others arrived in the US only last year. Similarly, the women bring a variety of educational and professional backgrounds to our project. In addition to the narrative workshops, the participants were invited to be professionally photographed by an IUPUC staff member. The intent of both creative processes - writing and photography - was to co-discover the experiences of the most marginalized population in the community. Although the staff photographer was also a student, students were not heavily involved in this initial effort for logistical reasons: the grant proposal was due after students' summer exodus and the writing workshops were conducted during the summer months. Student participation could have been improved upon by linking it with an

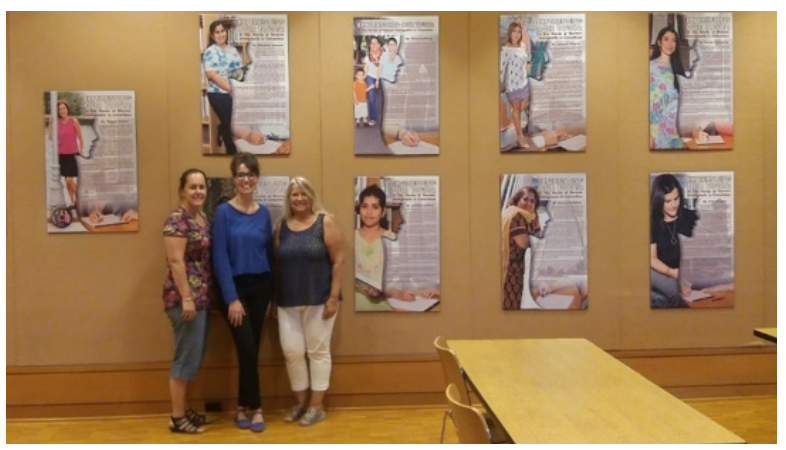

Anna Carmon, Aimee Zoeller, and Kate Wills at Columbus City Hall with Experiencing Our Town: In the Words of Immigrant Women display. Photo credit: George Towers

academic course in the fall or spring semester.

The resulting project was numerous and striking large-size posters with women situated in recognizable Columbus landmarks alongside their written narratives. In conjunction with Exhibit Columbus, the city's celebration of its architectural heritage, the posters were intentionally displayed in political spaces such as City Hall and community spaces such as The Commons and the Columbus Learning Center through the fall of 2017. Our project website (columbusimmigrantwomen.com) was launched in late August 2017 and is linked to the IUPUC website, the Human Rights page on the City of Columbus' website, and the Columbus Area Multi-Ethnic organization (CAMEO) website. In May 2019, the participants reconvened for a panel discussion as part of the Columbus Conversations series of public forums at the Mill Race Center. The women discussed their journeys to and experience of living in Columbus and participating in the project. The women's voices, their poster artifacts, and the website will continue to be presented to community audiences.

\section{References}

\author{
Ropeik, Annie. (2/16/ 2017).“Immigration Exec- \\ utive Order Causes Anxiety in VP Mike Pence's \\ Hometown," National Public Radio Morning Edi- \\ tion. Accessed on 9/1/2019 at https://www.npr. \\ org/2017/02/16/515454556immigration-executive-or- \\ der-causes-anxiety-in-vp-mike-pences-hometown
}

